\title{
VULNERABILIDADE NATURAL: A PERDA DE SOLO DA BACIA DO RIO CARINHANHA (MG/BA) USANDO UMA ABORDAGEM QUALITATIVA DA EQUAÇÃO UNIVERSAL DE PERDA DE SOLOS
}

\author{
KELLY MARIA RESENDE BORGES ${ }^{1}$ \\ OSMAR ABILIO CARVALHO JÚNIOR ${ }^{2}$ \\ EDER SOUZA MARTINS ${ }^{3}$ \\ ROBERTO ARNALDO TRANCOSO GOMES ${ }^{4}$ \\ RENATO FONTES GUIMARÃES ${ }^{5}$
}

\section{Introdução}

Para o planejamento territorial, uma das informações mais requisitadas é a vulnerabilidade natural à perda de solo. No decreto de lei número 4297, de junho de 2002, que estabelece os critérios mínimos para a elaboração do Zoneamento Ecológico-Econômico do Brasil (ZEE), é salientada a necessidade de obter indicadores da vulnerabilidade natural à perda de solo como um atributo integrante para delimitar a Fragilidade Natural Potencial.

Uma das principais proposições para a elaboração dessa informação é a metodologia proposta por Crepani et. al. (2001), que leva em consideração os conceitos da Ecodinâmica (Tricart, 1977). Nessa metodologia, são definidas as unidades de paisagem natural a partir das seguintes componentes: geologia, geomorfologia, pedologia, vegetação/uso da terra e clima. Para cada componente da paisagem é atribuído um valor

\footnotetext{
${ }^{1}$ Instituto Brasileiro de Meio Ambiente e Recursos Naturais Renováveis - IBAMA

${ }^{2}$ Universidade de Brasília

${ }^{3}$ Embrapa Cerrados

${ }^{4}$ Universidade de Brasília

${ }^{5}$ Universidade de Brasília
} 
que representa uma escala de vulnerabilidade à perda de solo entre 1,0 e 3,0, sendo: (a) valores próximos de 1,0, que se caracterizam pelo predomínio dos processos de pedogênese; (b) valores ao redor de 2,0, que apresentam situações intermediárias e (c) valores próximos de 3,0, que se caracterizam pelo predomínio dos processos de morfogênese. $\mathrm{O}$ valor final para a vulnerabilidade natural à perda de solo é estabelecido pela média aritmética dos cinco atributos analisados. O método, apesar de simples de ser efetuado, possui seus critérios elaborados dentro de um grau de subjetividade, o que pode dificultar a comparação entre regiões.

Dentro do ZEEs, uma alternativa para obtenção da vulnerabilidade natural à perda de solo é o emprego da Equação Universal de Solos (EUPS) (Wischmeier \& Smith, 1978), que possui uma ampla utilização com diversos estudos para a sua calibração regional. A EUPS propõe estabelecer uma quantificação de perda de solo por erosão laminar. No entanto, necessita adequações regionais de suas formulações para obter maior precisão nas suas estimativas.

Todavia, para os estudos de ZEEs, a EUPS pode adquirir uma abordagem qualitativa em vez de sua proposição original, que é a quantificação. Mesmo não obtendo valores precisos de perdas de solo, o mapeamento pela EUPS salienta com grande precisão as áreas mais ou menos vulneráveis. Esta abordagem qualitativa não se limitaria à erosão laminar, pois os locais propícios para outros tipos de erosão também seriam detectados. Além disso, a utilização da EUPS diferencia-se da proposta anterior, por considerar como unidade de mapeamento a resolução das imagens utilizadas, variando de pixel a pixel, não ficando restrita a uma unidade de paisagem pré-estabelecida, a qual possui em comparação uma extensa expressão areal.

A EUPS calcula a perda de solo laminar (A) a partir da integração de fatores naturais e antrópicos, sendo expressa pela equação 1:

$$
\mathrm{A}=\mathrm{R} * \mathrm{~K} * \mathrm{~L} * \mathrm{~S} * \mathrm{C} * \mathrm{P}
$$

Onde "A" é a perda de solo laminar em t/ha.ano; "R" é o fator de erosividade das chuvas em $\mathrm{Mj} . \mathrm{mm} /$ ha.h.ano; "K" é o fator de erodibilidade do solo em t.h/Mj.mm; "L" é o fator comprimento de rampa (metro); "S" é a declividade (porcentagem); "C" é o fator uso e manejo (adimensional) e "P" é o fator práticas conservacionistas (adimensional). Esses fatores podem ser estimados e espacializados a partir de técnicas de geoprocessamento e sensoriamento remoto. Em escalas regionais, a EUPS 
é válida para estudos qualitativos, fornecendo uma estimativa inicial de áreas susceptíveis à erosão, com o propósito de auxiliar a gestão ambiental (Leprun, 1988; Araújo Junior, 2003).

Dentro deste contexto, o objetivo do presente trabalho é mapear e analisar a vulnerabilidade natural à perda de solo na bacia do rio Carinhanha, através da aplicação da EUPS, a fim de subsidiar seu planejamento territorial e ambiental.

A bacia do rio Carinhanha está na divisa dos estados de Minas Gerais e Bahia (Figura 1), na região do médio São Francisco, possuindo uma área aproximada de 1.730 .000 hectares. Essa bacia está dentro do Bioma Cerrado que sofre uma intensa retirada da vegetação natural para uso agropecuário (Rodrigues, 2002; Sano et al., 2009).

A ocupação da terra de forma desordenada e inadequada provoca a compactação do solo com a diminuição da infiltração da água, aumento do escoamento superficial, intensificação dos processos erosivos, perda da fertilidade natural e assoreamento de rios (Camapum de Carvalho et al., 2006).

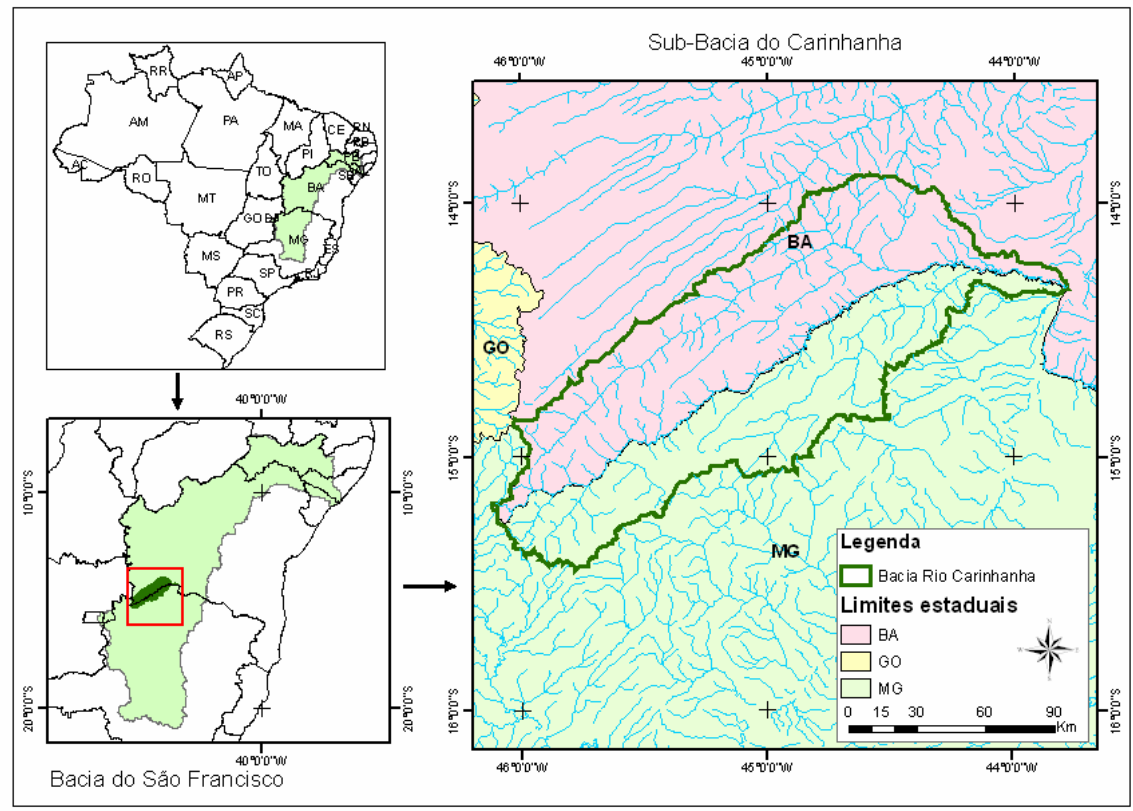

Figura 1 - Localização da sub-bacia do Rio Carinhanha. 
A bacia possui três tipologias climáticas, segundo a Classificação de Thornthwaite: úmido (porção oeste); subúmido seco (porção central) e semi-árido (extremo leste). A estratigrafia geológica é constituída na base pelas rochas paleozóicas do Grupo Bambuí (calcários, metassiltitos e ardósias) (Dardene, 1978), sobrepostas pelas rochas cretáceas do Grupo Urucuia, formados por sedimentos fluviais, eólicos e lacustres (Campos \& Dardenne, 1997) e no topo, recobrindo os platôs da bacia, ocorre a Formação Chapadão do período Cenozóico, constituído por uma sequência de arenitos e conglomerados friáveis e oxidados (Campos \& Dardenne, 1997). Localizada no Bioma Cerrado, apresenta as seguintes fitofisionomias: savanas, floresta estacional decidual, floresta estacional semidecidual e áreas de tensão ecológica (IBGE, 1992, 1993).

\section{Metodologia}

\section{Fator Topográfico (LS)}

O fator topográfico é constituído pelo comprimento de rampa (L) e a declividade (S). O comprimento de rampa é a distância entre o ponto de início do escoamento até o ponto onde o declive decresce, permitindo o início da deposição, ou onde a água encontra um canal bem definido. $\mathrm{O}$ Fator L, que é adimensional, adota o comprimento de rampa medido em metros, sem a unidade. O Fator $\mathrm{S}$ é caracterizado como o ângulo ou o índice de inclinação do terreno. O uso de métodos computacionais, a partir do Modelo Digital de Terreno (MDT), permite obter esses fatores da EUPS.

O MDT da bacia de estudo foi gerado a partir dos dados de curvas de nível, pontos cotados e hidrografia das cartas topográficas de 1:100.000, da Diretoria de Serviços Geográficos do Exército (DSG), que foram digitalizadas pela Companhia de Desenvolvimento dos Vales do São Francisco e do Parnaíba (CODEVASF).

O método utilizado para interpolação foi o Topogrid, desenvolvido para estudos hidrológicos (Hutchinson, 1989), considerando uma resolução espacial de 60 metros. A partir do MDT, foram gerados os atributos de terreno (direção de fluxo, declividade e área de contribuição). O Fator L pode ser obtido pela formulação proposta por Desmet e Govers (1996) (equação 2):

$$
L_{i j}=\left[\left(A_{i-j-i n}+D^{2}\right)^{m+1}-\left(A_{i-j-i n}\right)^{m+1}\right] /\left[D^{m+2} \cdot x_{i j}^{m} \cdot(22,13)^{m}\right]
$$


Onde " $\mathrm{A}_{\mathrm{i}-\mathrm{j}-\mathrm{in}}$ " é a área de contribuição da célula com coordenada (i,j) $\left(\mathrm{m}^{2}\right)$; "D" é o tamanho da célula $(\mathrm{m})$; “m” é o coeficiente função da declividade para a grade de célula com coordenada $(\mathrm{i}, \mathrm{j})$, onde o coeficiente " $\mathrm{m}$ " é obtido a partir das classes de declividade (sendo $\mathrm{m}=0,5$, se a declividade for $>5 \% ; \mathrm{m}=0,4$ para o intervalo de 3 a $5 \% ; \mathrm{m}=0,3$ para o intervalo de 1 a $3 \%$ e $m=0,2$ para declividade inferior a $1 \%$ ) e " $x$ " é o coeficiente função do aspecto para a grade de célula com coordenada (i,j), obtido pela equação $\mathrm{x}=\operatorname{sen} \alpha / \cos \alpha$, onde $\alpha$ é a direção do fluxo na vertente.

A área de contribuição foi calculada pelo método $\mathrm{D} \infty$, que calcula a direção do fluxo d'água de acordo com a declividade do terreno, distribuindo o fluxo proporcionalmente entre as células vizinhas (Tarboton, 1997). Esse procedimento foi utilizado para o cálculo do Fator LS para outras bacias do São Francisco e Parnaíba (Silva, 2004; Farinasso et al., 2006; Mata et al., 2007).

\section{Erosividade da Chuva: Fator $\mathbf{R}$}

A erosividade é diretamente proporcional à energia cinética $(\mathrm{E})$, em decorrência de sua intensidade máxima em 30 minutos $\left(\mathrm{I}_{30}\right)$ em uma unidade de área desprotegida de vegetação (Wischmeier e Smith, 1958). Apesar de o índice $\mathrm{EI}_{30}$ ser o mais adequado para a estimativa da erosividade, em muitas localidades, inexistem os dados pluviográficos para o seu cálculo. Uma alternativa a isso, é o Índice de Erosividade (EI) proposta por Lombardi Neto \& Moldenhauer (1992) para o município de Campinas, que considera os seguintes parâmetros determinados por uma estação pluviométrica: precipitação média mensal em milímetro (r) e de precipitação média anual em milímetro (p) (equação 3).

$$
\mathrm{EI}=67,355\left(\mathrm{r}^{2} / \mathrm{P}\right)^{0,85}
$$

O índice de erosividade média anual da precipitação de um dado local é então computado como o somatório dos valores dos índices médios mensais dos índices de erosão (EI), expresso pela equação 4 (Lombardi Neto e Moldenhauer, 1992):

$$
\mathrm{R}=\Sigma \mathrm{EI}
$$

Como na área de estudo não existem dados pluviográficos, foi utilizado para o cálculo do Fator R o método proposto por Lombardi Neto e Moldenhauer (1992). Na bacia do rio Carinhanha, foram utilizados dados 
diários de 21 estações pluviométricas localizadas dentro e fora da bacia, obtidos no site Hidroweb, da Agencia Nacional de Águas (http://hidroweb.ana.gov.br).

Para uma estimativa confiável, foram utilizadas séries históricas de 20 a 30 anos, conforme a disponibilidade dos dados. Após o cálculo do Fator R para todas as estações pluviométricas, foi feita uma interpolação dos pontos utilizando-se o método Topogrid (Hutchinson, 1989).

\section{Erodibilidade do solo: Fator $\mathrm{K}$}

$\mathrm{O}$ Fator $\mathrm{K}$ reflete a suscetibilidade à erosão ou a falta de capacidade de resistir aos processos erosivos de um determinado tipo de solo (Wischmeier \& Smith, 1978). As propriedades do solo que influenciam a erodibilidade pela água são aquelas que: (a) afetam a velocidade de infiltração, permeabilidade e capacidade total de armazenamento de água e (b) resistem às forças de dispersão, salpico, abrasão e transporte pela chuva e escoamento (Wischmeier \& Smith, 1965). Portanto, esse fator depende das características intrínsecas do solo e de fatores subsidiários, como ciclos de umedecimento e secagem, além da composição química da água nele presente (Vilar \& Prandi, 1993).

O Fator K é determinado experimentalmente em parcelas unitárias, sendo expresso como a perda de solo (A) por unidade de índice de erosão da chuva (EI), considerando todos os demais fatores da EUPS com valor unitário (Bertoni \& Lombardi Neto, 1990) (equação 5):

$$
K=A / E I
$$

No entanto, medidas experimentais do valor de $\mathrm{K}$, conforme as normas estabelecidas por Wischmeier \& Smith (1978), requerem muitos anos de estudos, além da dificuldade em se isolar os efeitos de solo dos demais fatores. Por isso, outros métodos foram propostos para a estimativa da erodibilidade do solo.

Para a bacia do São Francisco, Chaves (1994) desenvolveu uma equação para determinar indiretamente a erodibilidade dos solos (equação 6). Esse método leva em consideração a concentração de silte (SIL), carbono orgânico $(\mathrm{CO})$ e porcentagens de óxido de alumínio (OAL), óxido de ferro (OFE) e de óxido de silício (OSI), sendo todos eles extraíveis por ácido sulfúrico. 


$$
\begin{aligned}
\mathrm{K}= & 2,7 \cdot 10^{-3}(\mathrm{SIL})-5,23 \cdot 10^{-3}(\mathrm{OAL})+8,89 \cdot 10^{-3}(\mathrm{CO})^{2}+1,15 \cdot 10^{-2}(\mathrm{OFE})^{-1} \\
& +1,42 \cdot 10^{-4} \cdot\left(\mathrm{OSI}+\mathrm{OSI}^{2}\right)-1,89 \cdot 10^{-2} \cdot[\mathrm{OSI} /(\mathrm{OFE}+\mathrm{OAL})]^{2}
\end{aligned}
$$

Para a confecção do mapa de erodibilidade da bacia do Carinhanha, foi elaborado um mapa pedológico, utilizando como base o mapa de solos da CODEVASF na escala 1:500.000. Nessa etapa, foi realizado trabalho de campo, interpretação visual de imagens do sensor TM-Landsat e análise dos atributos de terreno proveniente do MDT. No trabalho de campo, foram feitas coletas em 67 pontos, em duas profundidades: $20 \mathrm{~cm}$ e $40 \mathrm{~cm}$, com exceção de alguns pontos onde o solo, por ser muito raso, permitiu apenas uma profundidade de coleta, totalizando 172 amostras. As análises químicas, físicas e de cor, bem como a identificação dos solos, foram realizadas pelo laboratório da EMBRAPA, em Cerrados.

Durante a elaboração do novo mapa de solos da bacia do Carinhanha, não foi possível individualizar os tipos de solo em todas as áreas, em função da baixa disponibilidade de informações e de amostras coletadas para análise. Por isso, a maior parte das unidades de mapeamento é formada por associações de tipos de solo. Nesses casos, o valor de K para cada classe foi obtido a partir do cálculo da média ponderada, baseada em uma estimativa do percentual de predominância de cada tipo de solo na associação. A Tabela 1 apresenta o valor do Fator K para as classes de solo presentes na bacia, conforme a proposição de Chaves (1994).

\begin{tabular}{|l|l|l|}
\hline $\begin{array}{l}\text { Tipo de solo (nomenclatura } \\
\text { antiga) }\end{array}$ & Nova nomenclatura & Fator K \\
\hline Solos Aluviais & Neossolo Flúvico & 0,047 \\
\hline Areias Quartzosas & Neossolo Quartzarênico & 0,0078 \\
\hline Cambissolos & Cambissolos & 0,06 \\
\hline Latossolo Amarelo & Latossolo Amarelo & 0,028 \\
\hline Latossolo Vermelho-Amarelo & Latossolo Vermelho-Amarelo & 0,02 \\
\hline Latossolo Vermelho-Escuro & Latossolo Vermelho & 0,013 \\
\hline Podzolico Vermelho-Amarelo & Argissolo Vermelho-Amarelo & 0,0293 \\
\hline Solos Litólicos & Neossolo Litólico & 0,035 \\
\hline
\end{tabular}

Tabela 1 - Fator K para cada tipo de solo (Chaves, 1994). 


\section{Uso e manejo da terra e práticas conservacionistas: Fator CP}

Os Fatores $\mathrm{C}$ e $\mathrm{P}$ estão relacionados ao uso da terra e à cobertura vegetal da bacia, podendo variar ao longo dos anos, em função de mudanças na forma e intensidade desse uso.

O Fator C é a relação esperada entre a perda de solo de um terreno, sob um uso e manejo qualquer, e as perdas correspondentes de um terreno de mesmo solo mantido continuamente descoberto. Desta forma, quanto maior a densidade da cobertura vegetal, menor é a perda de solo (Pinese Júnior et al., 2008).

$\mathrm{O}$ Fator $\mathrm{P}$ está relacionado às praticas conservacionistas e representa a relação entre a intensidade de perdas de solo com determinada prática de manejo e aquelas quando a cultura está plantada no sentido do declive.

Stein et al. (1987) consideram que os Fatores C e P só devem ser tratados separadamente quando o objetivo do trabalho for definir formas mais adequadas de produção agrícola, minimizando os impactos gerados sobre o meio físico. Entretanto, quando o trabalho enfoca a perda de solos por erosão, essas variáveis devem ser analisadas conjuntamente.

Nesse caso, os dados de C e P não são mais analisados em função do estádio de desenvolvimento da cultura, mas sim pelo uso e ocupação da terra. Stein et al. (1987) buscaram, então, integrar as variáveis CP, considerando o valor de $\mathrm{P}=1$ constante, por ser a pior situação quanto às perdas de solo em função das práticas conservacionistas.

No presente trabalho, o mapa de uso da terra e cobertura vegetal foi elaborado a partir técnicas de sensoriamento remoto. Foram utilizadas imagens do satélite TM-Landsat 5, referentes a três órbitas-pontos: 219070, 220-070 e 220-071, do ano de 2007. As imagens sofreram correções radiométrica e geométrica, a partir das imagens ortorretificadas do projeto Global Land Cover Facility (GLCF).

A classificação das imagens foi realizada em duas etapas: (a) classificação não-supervisionada pelo método ISODATA e (b) edição das classes previamente obtidas por interpretação visual em tela e trabalho de campo. O mapa final é constituído por 11 classes: água; área úmida/veredas; afloramento de rochas; cerrado; floresta estacional; mata ciliar; área de transição (cerrado/caatinga); área desmatada sem uso/vegetação secundária; área rural de uso diversificado; área urbana $\mathrm{e}$ solo exposto. Baseado nesse mapa, foram atribuídos os valores de CP para cada classe, a partir de uma adaptação da proposta de Stein et al. (1987). 


\section{Resultados}

\section{Resultado do Fator LS}

O MDT demonstra que a bacia do Carinhanha possui uma amplitude altimétrica de cerca 528 metros. Suas nascentes mais elevadas encontramse a uma cota altimétrica de 958 metros e sua desembocadura, no rio São Francisco, tem aproximadamente 430 metros de altitude. O mapa do Fator LS evidencia que os maiores valores encontram-se relacionados às declividades mais altas com convergência de fluxo localizadas, principalmente, nas bordas das chapadas e próximos aos afloramentos de calcário (Figura 2). As áreas mais planas da bacia, como os topos de chapadas e a área de depressão fluvial, próximas ao rio São Francisco, apresentam os menores valores de LS.

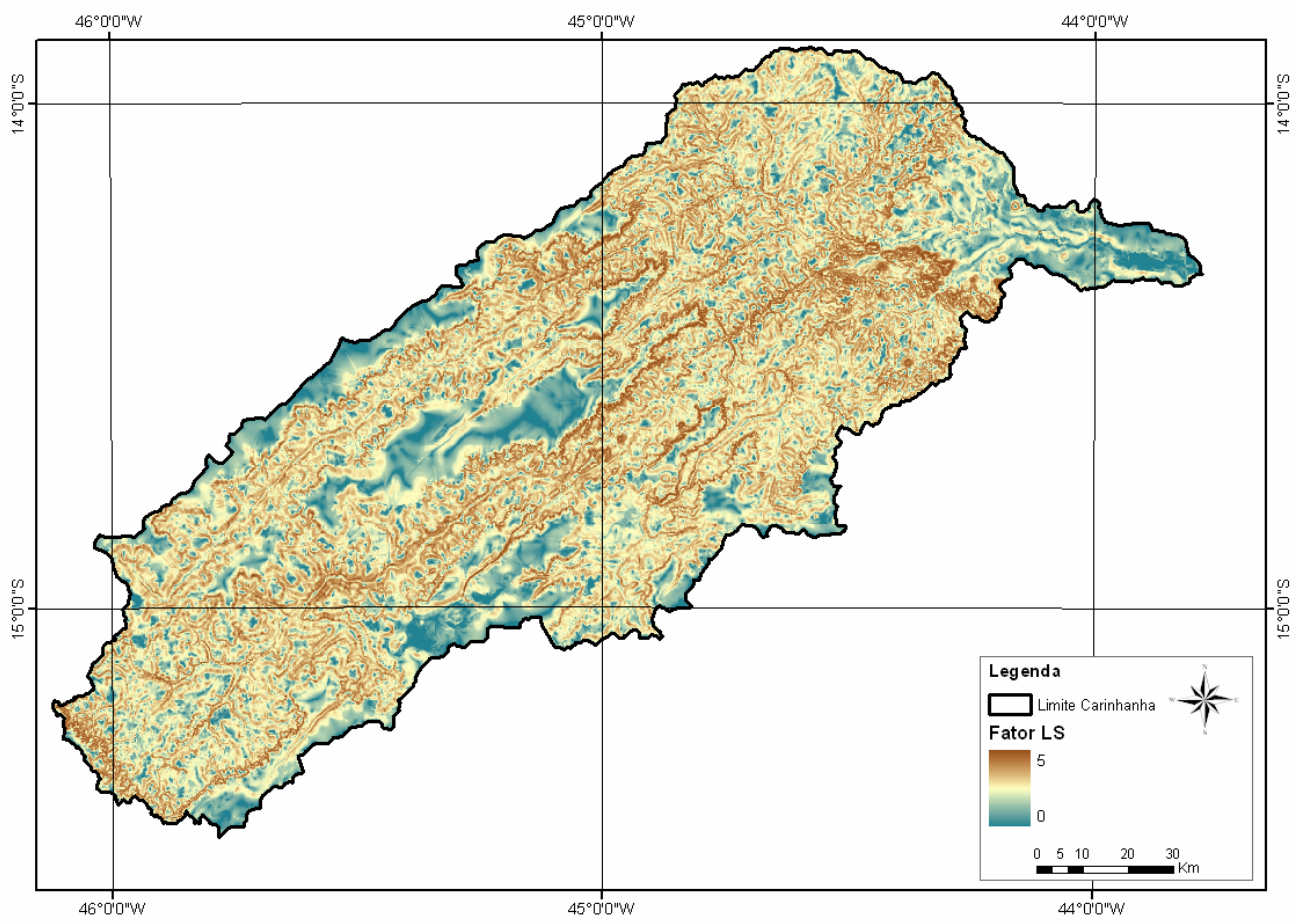

Figura 2 - Mapa do Fator LS realçado pela função logarítmica. 


\section{Resultado do Fator $\mathbf{R}$}

Os resultados da análise da erosividade das chuvas na Sub-bacia do rio Carinhanha mostram que o valor médio anual encontrado para a área de estudo foi de $6.491 \mathrm{MJ} . \mathrm{mm} / \mathrm{ha}$.h.ano, variando de $5.584 \mathrm{MJ} . \mathrm{mm} / \mathrm{ha}$.h.ano a 7.664 MJ.mm/ha.h.ano (Figura 3).

O mapa do Fator $\mathrm{R}$ mostrou-se coerente com o mapa da Classificação Climática. A porção oeste da bacia, onde o clima é classificado como úmido, o valor do Fator R é o mais alto, de 6800 até $7600 \mathrm{MJ} . \mathrm{mm} /$ ha.h.ano. Há uma tendência de diminuição dos valores de erosividade de oeste para leste, passando pela área classificada como clima subúmido seco até o clima semi-árido, na porção leste da bacia, área mais próxima à foz do Carinhanha com rio São Francisco.

Os menores valores de $\mathrm{R}$ são encontrados na porção da bacia classificada como clima semi-árido, cuja característica principal é justamente a deficiência hídrica.

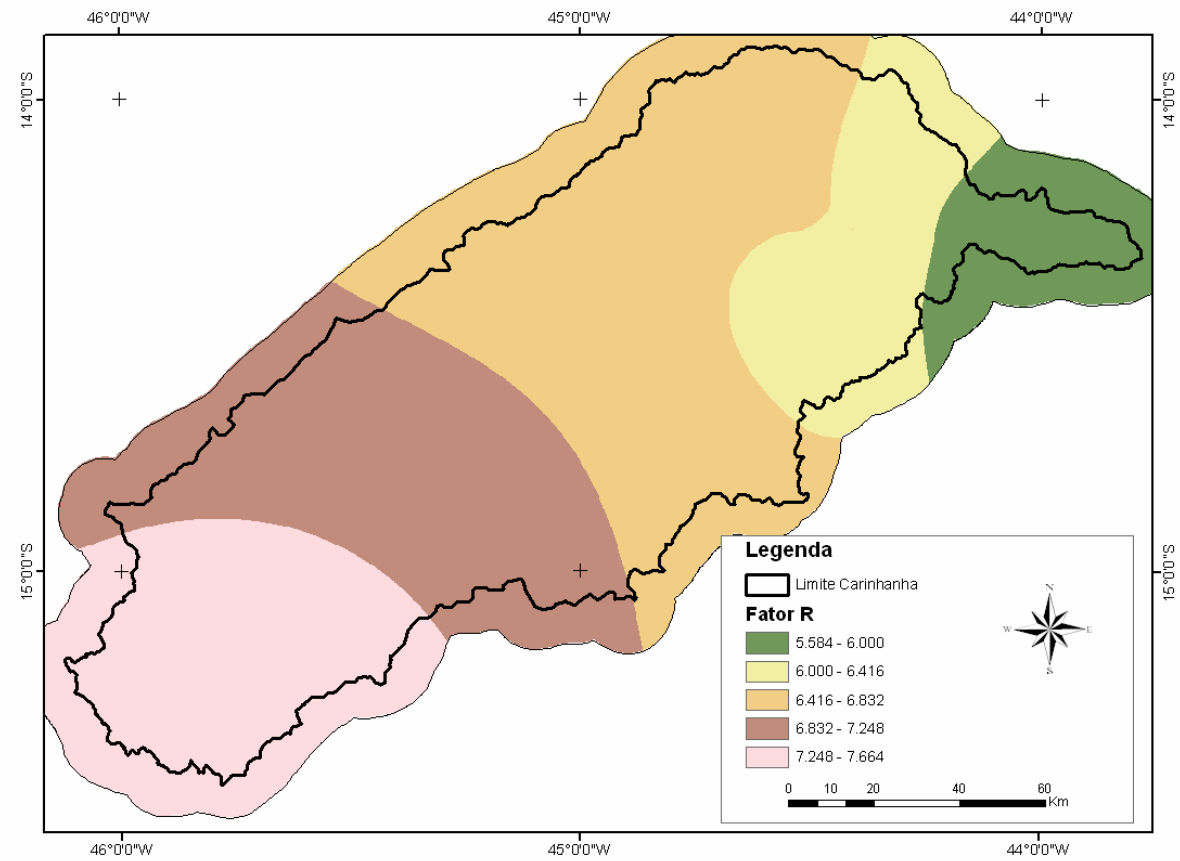

Figura 3 - Mapa do Fator R da bacia do Carinhanha. 


\section{Resultado do Fator K}

A Figura 4 mostra o mapa de solos da bacia do Carinhanha e a Tabela 2 apresenta os dados de ocorrência das unidades mapeadas (Borges, 2009). O mapa de erodibilidade foi gerado a partir do cálculo de K para cada classe do mapa pedológico (Tabela 3 e Figura 5) e foi dividido nas classes adaptadas de Carvalho (1994): baixa, média e alta.

As unidades com alta erodibilidade correspondem a 5,7\% da área, sendo: Neossolo Flúvico, Neossolo Litólico + Cambissolo; Argissolo + Cambissolo; Cambissolo + Neossolo Litólico + Latossolo Vermelhoamarelo + Neossolo Quartzarênico e Plintossolo + Gleissolo.

As unidades de solo com erodibilidade média predominam na bacia (47,89\%), sendo em ordem decrescente: Latossolo Amarelo + Argissolo; Latossolo Amarelo; Latossolo Vermelho-amarelo + Latossolo Amarelo; Neossolo Quartzarênico + Latossolo Amarelo.

As unidades com maior resistência à erodibilidade do solo na bacia são o Neossolo Quartzarênico e o Gleissolo, além da classe Afloramento Rochoso, cujo Fator K é igual a zero.

As três classes juntas ocupam 46,41\% da área de estudo, com destaque para os Neossolos Quartzarênicos, que sozinhos ocupam 42,17\% da área. Portanto, a maior parte da bacia do Carinhanha, 94,3\% da área, possui solos com erodibilidade média e baixa. 


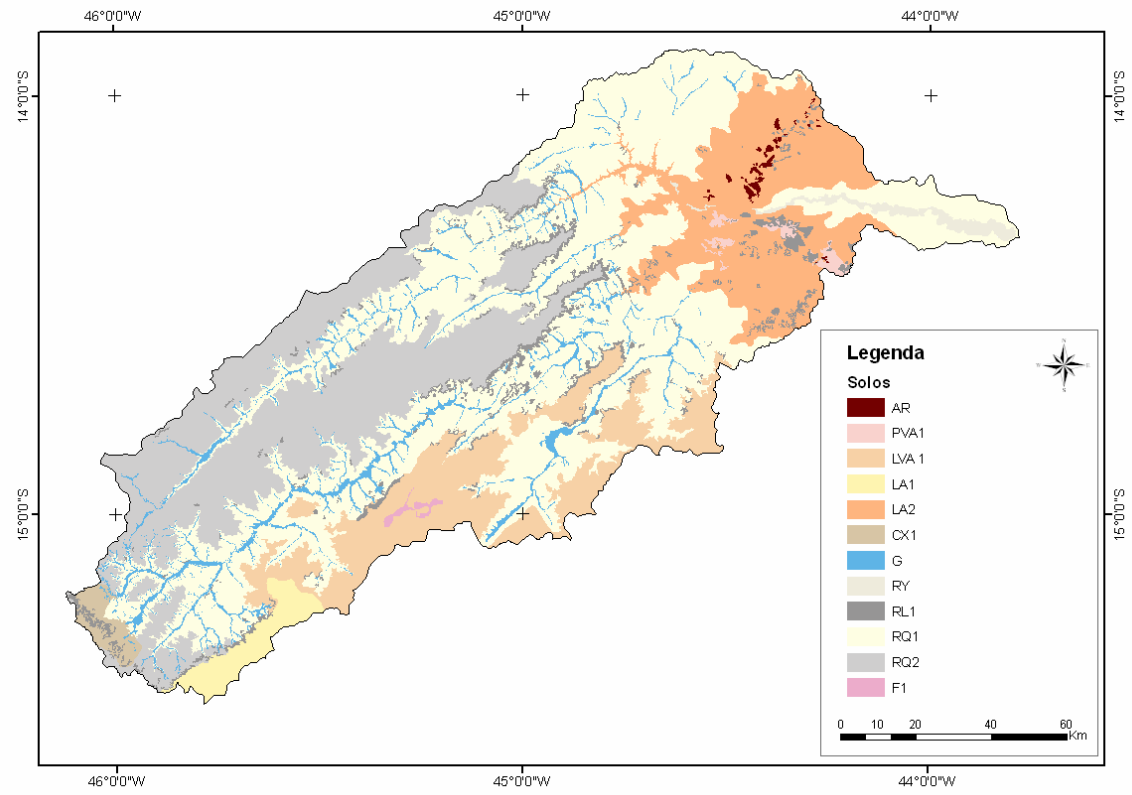

Figura 4 - Mapa de solos da Bacia do Carinhanha (Borges, 2009).

\begin{tabular}{|c|c|c|c|c|}
\hline $\begin{array}{l}\text { Solo }-1^{\circ} \\
\text { Nível }\end{array}$ & Sigla & Unidade de mapeamento & $\begin{array}{l}\text { Area } \\
\text { (ha) }\end{array}$ & $\begin{array}{l}\% \\
\text { área }\end{array}$ \\
\hline $\begin{array}{l}\text { Afloramento } \\
\text { Rochoso }\end{array}$ & AR & Afloramento Rochoso & 4.672 & 0,27 \\
\hline Argissolo & PVA1 & $\begin{array}{l}\text { Associação de: Argissolo Vermelho- } \\
\text { amarelo + Cambissolo Háplico }\end{array}$ & 8.306 & 0,48 \\
\hline \multirow[t]{3}{*}{ Latossolo } & LVA1 & $\begin{array}{l}\text { Associação de: Latossolo Vermelho- } \\
\text { amarelo + Latossolo Amarelo }\end{array}$ & 185.329 & 10,71 \\
\hline & LA1 & Latossolo Amarelo & 33.397 & 1,93 \\
\hline & LA2 & $\begin{array}{l}\text { Associação de: Latossolo Amarelo + } \\
\text { Argissolo Vermelho-amarelo }\end{array}$ & 222.187 & 12,84 \\
\hline Cambissolo & CX1 & 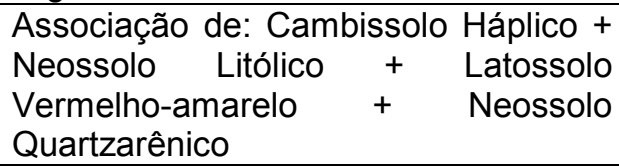 & 15.401 & 0,89 \\
\hline Gleissolo & G & Gleissolo & 68.698 & 3,97 \\
\hline \multirow[t]{2}{*}{ Neossolo } & RY & Neossolo Flúvico & 15.228 & 0,89 \\
\hline & RL1 & Associação de: Neossolo Litólico + & 56.931 & 3,29 \\
\hline
\end{tabular}




\begin{tabular}{|l|l|l|r|r|}
\hline & & Cambissolo Háplico & & \\
\cline { 2 - 5 } & RQ1 & Neossolo Quartzarênico & 729.723 & 42,17 \\
\cline { 2 - 5 } RQ2 & $\begin{array}{l}\text { Associação Neossolo } \\
\text { Quartzarênico + Latossolo Amarelo }\end{array}$ & 387.790 & 22,41 \\
\hline Plintossolo & F1 & Associação de: Plintossolo + Gleissolo & 2.770 & 0,16 \\
\hline & & & $\begin{array}{r}1.730 .4 \\
32\end{array}$ & 100 \\
\hline
\end{tabular}

Tabela 2 - Unidades de mapeamento de Solos (Borges, 2009).

\begin{tabular}{|c|c|c|c|c|c|c|c|c|c|}
\hline \multirow[t]{2}{*}{ Unidade } & \multicolumn{2}{|c|}{ Tipo 1} & \multicolumn{2}{|c|}{ Tipo 2} & \multicolumn{2}{|c|}{ Tipo 3} & \multicolumn{2}{|c|}{ Tipo 4} & \multirow{2}{*}{$\begin{array}{c}\text { Valor } \\
\mathrm{K}\end{array}$} \\
\hline & $\mathrm{K}$ & $\%$ & $\mathrm{~K}$ & $\%$ & $\mathrm{~K}$ & $\%$ & $\mathrm{~K}$ & $\%$ & \\
\hline $\begin{array}{l}\text { Afloramento } \\
\text { rochoso }\end{array}$ & 0 & 100 & - & - & - & - & - & - & 0 \\
\hline $\begin{array}{l}\text { Argissolo } \\
\text { Cambissolo }\end{array}$ & 0,0293 & 60 & $\begin{array}{c}0,06 \\
00\end{array}$ & $\begin{array}{l}4 \\
0\end{array}$ & - & - & - & - & $\begin{array}{c}0,041 \\
58\end{array}$ \\
\hline $\begin{array}{l}\text { Cambissolo } \\
\text { Neossolo } \\
\text { Litólico } \\
\text { Latossolo } \\
\text { Vermelho } \\
\text { amarelo } \\
\text { Neossolo } \\
\text { Quartzarênico }\end{array}$ & 0,0600 & 40 & $\begin{array}{c}0,03 \\
50\end{array}$ & $\begin{array}{l}2 \\
0\end{array}$ & $\begin{array}{c}0,02 \\
0\end{array}$ & $\begin{array}{l}2 \\
0\end{array}$ & $\begin{array}{c}0,00 \\
78\end{array}$ & 20 & $\begin{array}{c}0,036 \\
56\end{array}$ \\
\hline $\begin{array}{l}\text { Latossolo } \\
\text { Amarelo }\end{array}$ & 0,028 & 100 & - & - & - & - & - & - & 0,028 \\
\hline $\begin{array}{l}\text { Latossolo } \\
\text { Amarelo } \\
\text { Argissolo } \\
\end{array}$ & 0,028 & 60 & $\begin{array}{c}0,02 \\
93\end{array}$ & $\begin{array}{l}4 \\
0\end{array}$ & - & - & - & - & $\begin{array}{c}0,028 \\
52\end{array}$ \\
\hline $\begin{array}{l}\text { Latossolo } \\
\text { Vermelho- } \\
\text { amarelo } \\
\text { Latossolo } \\
\text { Amarelo }\end{array}$ & 0,020 & 60 & $\begin{array}{c}0,02 \\
8\end{array}$ & $\begin{array}{l}4 \\
0\end{array}$ & - & - & - & - & $\begin{array}{c}0,023 \\
20\end{array}$ \\
\hline $\begin{array}{l}\text { Neossolo } \\
\text { Flúvico }\end{array}$ & 0,0470 & 100 & - & - & - & - & - & - & $\begin{array}{c}0,047 \\
0\end{array}$ \\
\hline $\begin{array}{l}\text { Neossolo } \\
\text { Litólico } \\
\text { Cambissolo }\end{array}$ & 0,035 & 60 & $\begin{array}{c}0,06 \\
0\end{array}$ & $\begin{array}{l}4 \\
0\end{array}$ & - & - & - & - & $\begin{array}{c}0,045 \\
0\end{array}$ \\
\hline $\begin{array}{l}\text { Neossolo } \\
\text { Quartzarênico }\end{array}$ & 0,0078 & 100 & - & - & - & - & - & - & $\begin{array}{c}0,007 \\
8\end{array}$ \\
\hline Neossolo & 0,0078 & 60 & 0,02 & 4 & - & - & - & - & 0,015 \\
\hline
\end{tabular}




\begin{tabular}{|l|c|c|c|c|c|c|c|c|c|}
\hline $\begin{array}{l}\text { Quartzarênico + } \\
\text { Latossolo } \\
\text { Amarelo }\end{array}$ & & & 8 & 0 & & & & & 88 \\
\hline $\begin{array}{l}\text { Plintossolo + } \\
\text { Gleissolo }\end{array}$ & 0,055 & 60 & $\begin{array}{c}0,00 \\
81\end{array}$ & $\begin{array}{c}4 \\
0\end{array}$ & - & - & - & - & 0,036 \\
\hline Gleissolo & 0,0081 & 100 & - & - & - & - & - & - & $\begin{array}{c}0,008 \\
1\end{array}$ \\
\hline
\end{tabular}

Tabela 3 - Unidades de mapeamento de solo e Fator K.

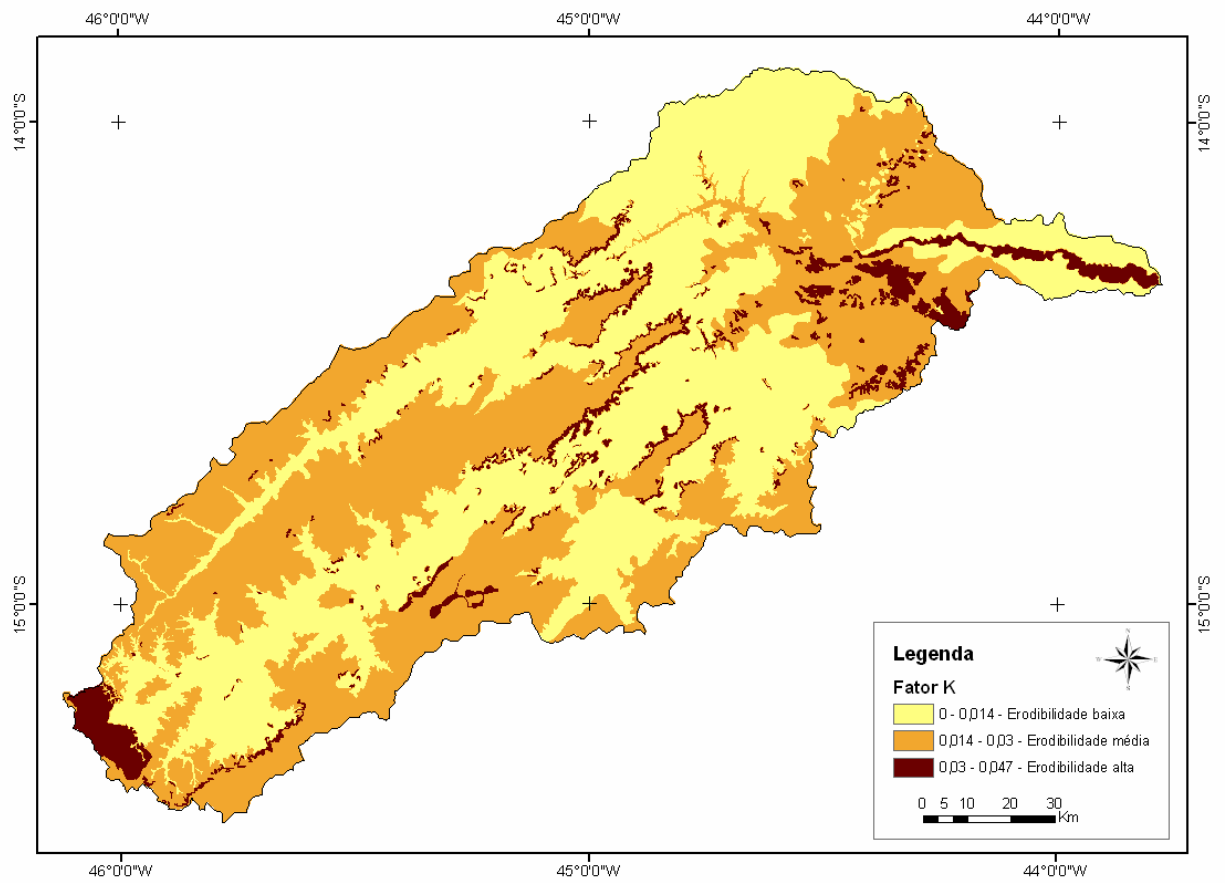

Figura 5 - Mapa do Fator K da bacia do Carinhanha.

\section{Resultados dos Fatores CP}

A Figura 6 mostra o Mapa de Uso da Terra e Cobertura Vegetal resultante da classificação das imagens do sensor TM-Landsat balizado pelo trabalho de campo. A Tabela 4 apresenta a área e o percentual ocupados por cada classe em hectares. 
$\mathrm{Na}$ área de estudo, predomina a classe Cerrado (70\%), composto pelos seus diversos tipos físionômicos (Cerrado Stricto Senso, Cerradão, Campo Limpo e Campo Sujo). Além do Cerrado, ocorre a presença das seguintes classes de vegetação natural: Floresta Estacional (3\%), Mata Ciliar $(1,7 \%)$, Áreas úmidas/Veredas $(1,6 \%)$ e área de transição entre Cerrado e a Caatinga (2,8\%). As classes de Mata Ciliar e Vereda apresentaram dificuldades para serem mapeadas na escala de trabalho, por se tratarem de áreas estreitas e alongadas. A área de transição ocorre na porção leste da bacia do Carinhanha, próximo ao rio São Francisco, e uma região mais povoada da bacia e encontra-se bastante degradada.

Desta forma, verifica-se a existência, ainda, de alta porcentagem de áreas preservadas, que conta com a presença do Parque Nacional Grande Sertão Veredas. No entanto, é importante salientar a eventual presença de vegetação secundária em estágios mais avançados de regeneração, devido às dificuldades de identificação nas imagens de satélite. Assim, observamse em diferentes locais diversos níveis de alterações, principalmente pelas queimadas constantes e a retirada esporádica da sua porção lenhosa.

A classe de maior complexidade na interpretação foi a Área Rural de Uso Diversificado ( $15 \%$ da área) composta, devido à escala de trabalho, pelas áreas de cultura, solo exposto, chácaras e pastagens. As áreas mapeadas como solo exposto estão próximas ao encontro do Carinhanha com o São Francisco. É uma área bastante atingida pelas queimadas e pela retirada indiscriminada da vegetação natural para geração de carvão vegetal. Como o solo é muito arenoso, a vegetação não consegue se regenerar e as manchas de areia tendem a aumentar.

Por ser uma região de baixa densidade demográfica, as áreas urbanas ocupam apenas $0,05 \%$ da bacia onde, dos 12 municípios presentes, apenas cinco possuem sua área urbana dentro dela, são eles: Chapada Gaúcha, Montalvânia, Juvenília, Feira da Mata e Cocos.

As classes afloramento de rochas, água e solo exposto ocupam cada uma menos de $1 \%$ da área. Os afloramentos de rocha que ocorrem na área são, na maioria, de origem calcária, apesar de, no campo, ser possível avistar afloramentos de arenitos da Formação Urucuia que, por serem muito pontuais, não foram mapeados nessa escala.

A classe área desmatada sem uso/vegetação secundária (4\%) foi individualizada por ser característica da região. Nela, a vegetação natural é retirada para ser transformada em carvão vegetal e abandonada, ficando sem nenhum tipo de uso por longo período de tempo. Ocorre uma 
regeneração lenta e empobrecida da vegetação nativa, provavelmente em função da baixa qualidade dos solos e da deficiência hídrica em boa parte do ano.

Neste trabalho, para a confecção do mapa do Fator CP, foi adotada a integração dos fatores antrópicos da EUPS para as classes de uso e cobertura vegetal (Figura 7). A Tabela 5 apresenta os valores adotados que foram adaptados do trabalho de Stein et al. (1987).

\begin{tabular}{|l|r|r|}
\hline Uso & \multicolumn{1}{|c|}{ Hectares } & \multicolumn{1}{c|}{$\%$} \\
\hline Água & 138 & 0,008 \\
\hline Afloramento de rochas & 6.178 & 0,357 \\
\hline $\begin{array}{l}\text { Área desmatada sem uso / Vegetação } \\
\text { Secundária }\end{array}$ & 72.349 & 4,181 \\
\hline Área de transição (alterada ou não) & 49.490 & 2,860 \\
\hline Área urbana & 795 & 0,046 \\
\hline Área rural de uso diversificado & 269.411 & 15,569 \\
\hline Cerrado & 1.219 .418 & 70,469 \\
\hline Floresta estacional & 51.273 & 2,963 \\
\hline Mata ciliar & 30.854 & 1,783 \\
\hline Solo exposto & 1.869 & 0,108 \\
\hline Área úmida / vereda & 28.657 & 1,656 \\
\hline Total & 1.730 .432 & 100 \\
\hline
\end{tabular}

Tabela 4 - Classes de uso da terra e cobertura vegetal da bacia do Carinhanha.

\begin{tabular}{|l|c|}
\hline Uso da terra/ cobertura & Fator CP \\
\hline Afloramento Rochoso & 0,000 \\
\hline Urbano & 0,000 \\
\hline Corpos d'água & 0,000 \\
\hline Mata Nativa (Ciliar / Floresta Estacional) & 0,00004 \\
\hline Cerrado & 0,0007 \\
\hline Área de transição cerrado / caatinga & 0,0007 \\
\hline Vegetação Secundária (área desmatada sem uso) & 0,01 \\
\hline Área alagável / úmida / veredas & 0,01 \\
\hline Área rural de uso diversificado & 0,2 \\
\hline Solo exposto & 1,000 \\
\hline
\end{tabular}

Tabela 5 - Valores de CP para os tipos de uso e cobertura vegetal na bacia do Carinhanha. 


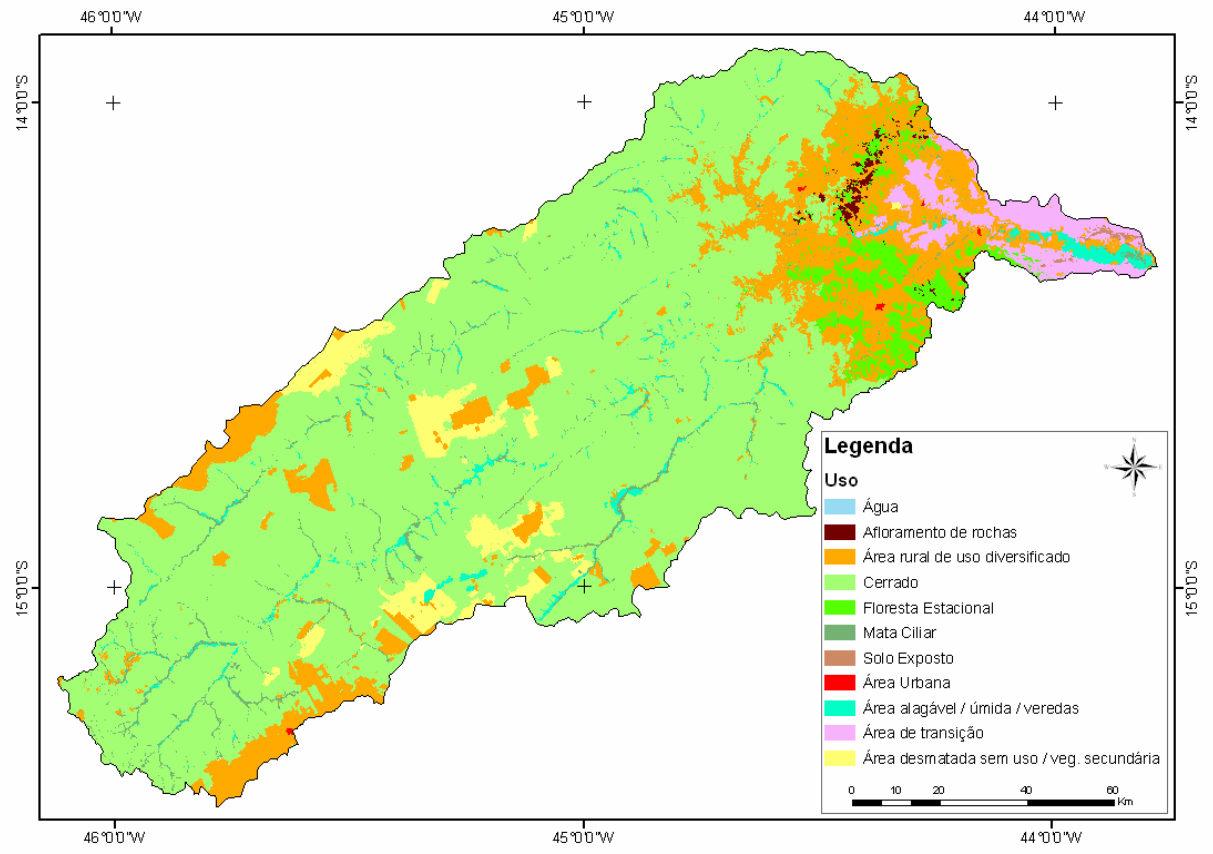

Figura 6 - Mapa de Uso da Terra e Cobertura Vegetal da Bacia do Carinhanha. 


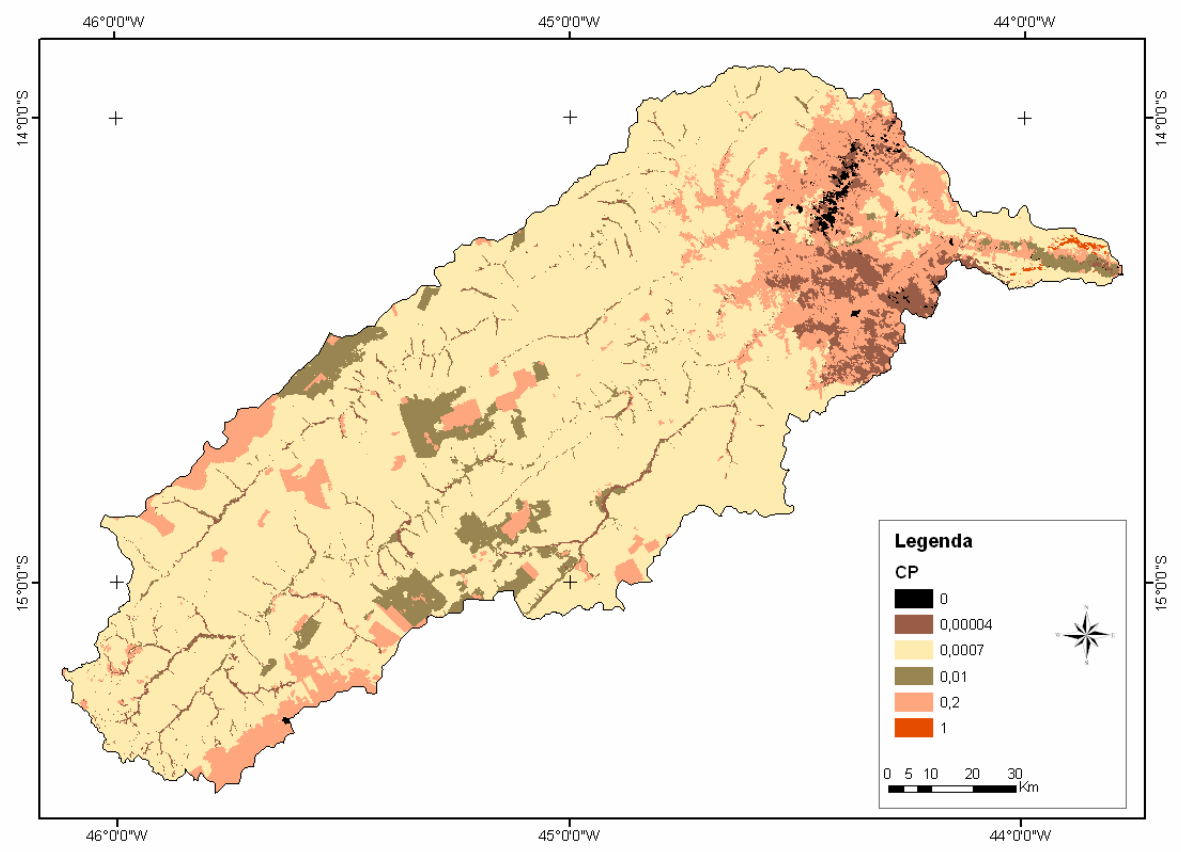

Figura 7 - Mapa do Fator CP da bacia do Carinhanha.

\section{Erosão atual na bacia do Carinhanha}

O Mapa de Erosão Atual (Ea) da bacia do Carinhanha foi obtido a partir do cruzamento dos mapas dos Fatores LS (Figura 2), R (Figura 3), K (Figura 5), e CP (Figura 7). A Figura 8 mostra o Mapa de Erosão Atual para a bacia do Rio Carinhanha, em que foram divididos em cinco classes de natureza qualitativa, conforme o proposto por Carvalho (1994).

A classe nula a pequena ocupa a maior parte de bacia (89,37\%). Essa característica deve-se ao fato de a bacia possuir um relevo predominantemente plano ou suave ondulado $(94 \%)$ e com predominância de cobertura de vegetação natural $(70 \%)$.

A distribuição espacial dos valores de erosão atual está associada, principalmente, ao tipo de uso do solo e cobertura vegetal, ou seja, aos Fatores CP. Desta forma, os maiores valores de Erosão Atual (Ea) são justamente as que foram classificadas como solo exposto e áreas rurais de uso diversificado. 
A área mais crítica com relação à perda de solos é onde há maior ocupação, localizada na porção leste da Bacia, região de maior densidade demográfica e onde se concentra a maior parte das atividades produtivas.

A influência do uso e ocupação do solo e cobertura vegetal torna-se ainda mais visível quando é comparada ao Mapa de Erosão Atual, reclassificado com o Mapa de Erosão Potencial considerando as mesmas classes (Figura 9). Percebe que a mesma área pode sofrer perdas de solo muito mais severas quando não há proteção da cobertura vegetal (Tabela 7).

Nesta nova configuração, o potencial de perda de solos da área de estudo seria mais de $24 \%$ na classe forte e muito forte. A mudança de cenário com a retirada total da cobertura vegetal mostra o agravamento da erosão, caso não haja um planejamento que leve em conta a vulnerabilidade ambiental da bacia do Carinhanha.

\begin{tabular}{|l|r|c|}
\hline \multirow{2}{*}{ Classe de degradação } & \multicolumn{2}{|c|}{ Magnitude da erosão do solo } \\
\cline { 2 - 3 } & Área (ha) & Extensão da área (\%) \\
\hline Nula a pequena & 1.546 .487 & 89,37 \\
\hline Moderada & 30.975 & 1,79 \\
\hline Média & 109.190 & 6,31 \\
\hline Média a forte & 43.261 & 2,50 \\
\hline Forte & 519 & 0,03 \\
\hline Total & 1.730 .432 & 100 \\
\hline
\end{tabular}

Tabela 6 - Classes de Erosão Atual (2007).

\begin{tabular}{|l|r|r|}
\hline \multirow{2}{*}{ Classe de degradação } & \multicolumn{2}{|c|}{ Magnitude da erosão do solo } \\
\cline { 2 - 3 } & Área (ha) & \multicolumn{1}{c|}{ Extensão da área (\%) } \\
\hline Nula a pequena & 250.394 & 14,47 \\
\hline Moderada & 36.512 & 2,11 \\
\hline Média & 398.518 & 23,03 \\
\hline Média a forte & 621.052 & 35,89 \\
\hline Forte & 215.093 & 12,43 \\
\hline Muito forte & 208.863 & 12,07 \\
\hline Total & 1.730 .432 & 100 \\
\hline
\end{tabular}

Tabela 7 - Classes de Erosão Potencial. 


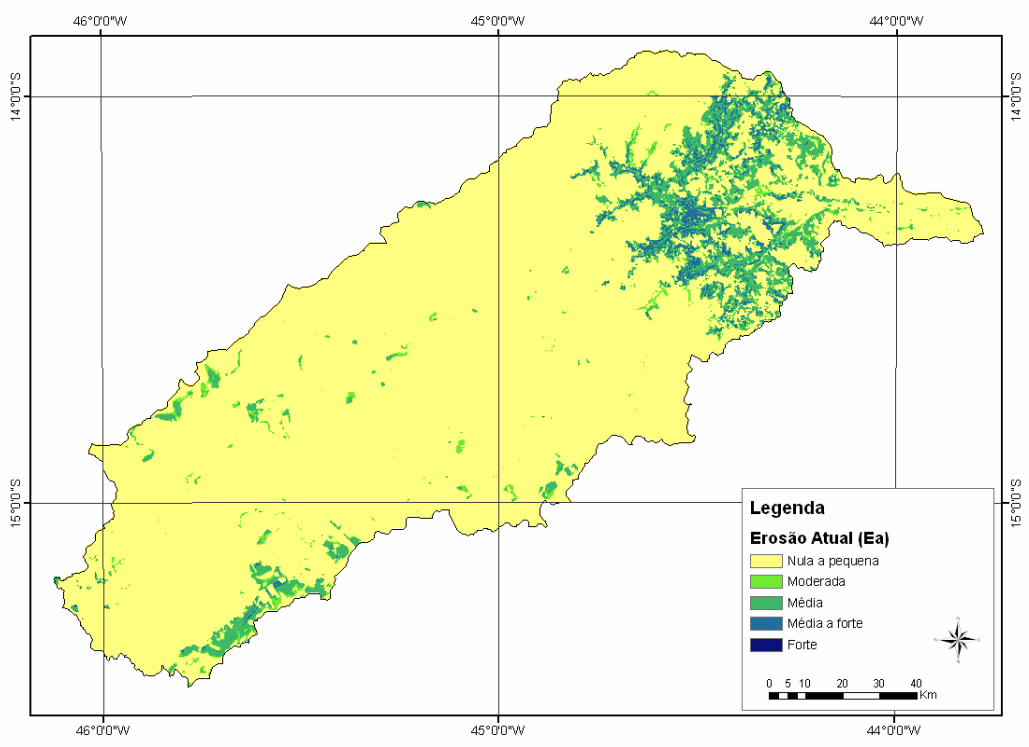

Figura 8 - Mapa de Erosão Atual (Ea) da Bacia do Carinhanha.

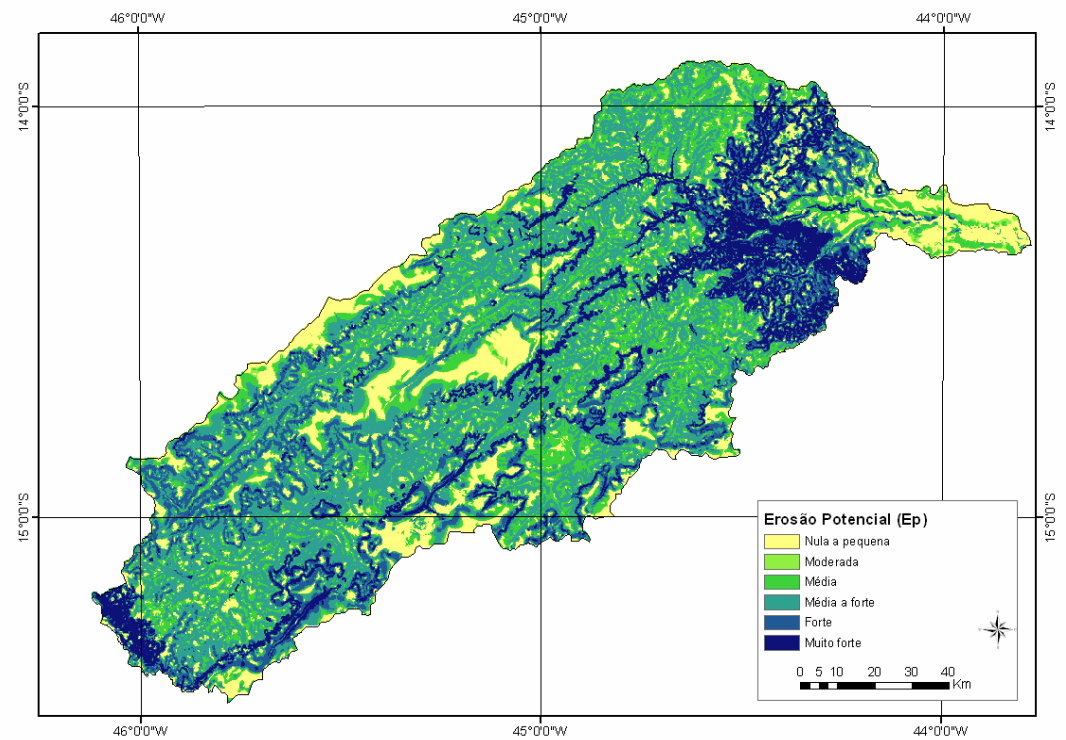

Figura 9 - Mapa de Erosão Potencial reclassificado. 


\section{Conclusões}

Apesar de a EUPS necessitar de validações para obtenção de dados quantitativos precisos, o seu emprego, a partir do conhecimento existente, permite identificar as áreas mais vulneráveis à perda de solo e estabelece critérios de prevenção e de uso de práticas conservacionistas. Tal equação foi criada para aplicação em pequenas áreas de clima temperado, entretanto, seu uso em regiões tropicais e em escala regional é possível, principalmente, em um enfoque qualitativo, a fim de discriminar áreas de maior e menor vulnerabilidade natural à perda de solos (Hoyos, 2005; Stein et al, 1987; Bloise et al., 2001).

Nesta abordagem qualitativa, as áreas mapeadas não são restritas apenas à erosão laminar, salientando também áreas onde ocorrem outros tipos de erosão. Desta forma, o modelo da EUPS permite simular cenário e indicar a capacidade de uso, compreendendo os diferentes ambientes presentes na bacia hidrográfica.

Esta informação, ainda que qualitativa, fornece subsídios relevantes para a elaboração do ZEE. A formulação da EUPS, por ser proveniente de um modelo estatístico para a quantificação, estabelece uma melhor precisão das áreas vulneráveis e uma fácil comparação entre dados de diferentes regiões. A adequação do modelo da USLE para o SIG aumenta a rapidez e a eficiência dos resultados espaciais, onde a unidade básica de mapeamento é determinada pela resolução espacial do pixel.

Desta forma, o emprego do modelo da EUPS permitiu o desenvolvimento de um conjunto de mapas relevantes para o conhecimento das características físicas e antrópicas da bacia em estudo, como: mapas dos atributos de terreno (declividade, direção de fluxo, área de contribuição, Fator LS), erodibilidade, erosividade, uso da terra e cobertura vegetal.

A bacia do Carinhanha é uma das poucas sub-bacias do rio São Francisco pertencentes ao Oeste da Bahia, que apresentam uma alta porcentagem de áreas de cobertura vegetal natural. Esta situação concede à bacia do Carinhanha uma grande importância, pois permite a adoção de políticas de manejo e conservação do solo com antecedência ao uso exploratório.

Apesar de a bacia possuir pouco uso agropecuário, o avanço do desmatamento é uma realidade. A agricultura mecanizada intensiva vem avançando, principalmente, nos municípios de Chapada Gaúcha (MG) e 
Cocos (BA). Observa-se um aumento da produção de carvão vegetal, o que vem destruindo a vegetação nativa. Muitas áreas são desmatadas e abandonadas e a exposição do solo, normalmente pobre em nutrientes, dificulta a regeneração da vegetação e aumenta os riscos de erosão.

VULNERABILIDADE NATURAL: A PERDA DE SOLO DA BACIA DO RIO CARINHANHA (MG/BA) USANDO UMA ABORDAGEM QUALITATIVA DA EQUAÇÃO UNIVERSAL DE PERDA DE SOLOS

Resumo: O objetivo deste trabalho foi mapear e analisar a susceptibilidade erosiva da bacia do rio Carinhanha por meio da aplicação da Equação Universal de Perda de Solo (EUPS), a fim de subsidiar o planejamento territorial ambiental na área. A bacia do rio carinhanha é tributária da bacia do rio São Francisco, tem aproximadamente 1.700 .000 hectares e faz parte do Bioma Cerrado, um dos mais ameaçados pela intensificação do uso do solo e retirada da vegetação natural. A metodologia utilizou dados de chuva das estações pluviométricas para a obtenção do Fator R. O Fator K foi gerado a partir de informações cartográficas e de dados de solos da bacia. O Fator Topográfico (LS) foi obtido do MDT, gerado através de ferramentas de SIG. Dados de interpretação de imagem de satélite foram utilizados para a obtenção dos Fatores CP. A aplicação da EUPS permitiu uma avaliação qualitativa do potencial erosivo e da erosão atual na bacia do Carinhanha. A área possui uma baixa taxa de erosão atual por possuir boas condições de cobertura vegetal natural. No entanto, se essa cobertura continuar sofrendo grandes alterações, o cenário pode mudar. Os resultados mostram a distribuição espacial das áreas propensas à erosão na bacia, onde práticas conservacionistas podem ser satisfatórias na prevenção da perda de solo por erosão.

Palavras-chave: erosão, EUPS, Bioma Cerrado, Sistema de Informação Geográfica.

NATURAL VULNERABILITY TO SOIL: LOSS AT THE CARINHANHA RIVER BASIN (MG/BA) USING A QUALITATIVE APPROACH OF THE UNIVERSAL SOIL LOSS EQUATION

Abstract: This paper aims to analyze and to map erosion susceptibility of Carinhanha River Basin applying the Universal Soil Loss Equation 
(USLE) in order to support territorial environmental planning. Carinhanha River Basin, with 1,700,000 hectares, is a tributary of São Francisco River and it is located on Cerrado Biome, one of the most threatened with the intensification of land use and removal of natural vegetation. The methodology used rainfall data from pluviometric stations in order to obtain R-factor. K-factor was achieved by making a more detailed map from the previous map and the analysis of soil samples collected. In order to obtain Topographic Factor (LS), DEM was made from GIS tools. Remote Sensing data provided information for CP factors. The USLE application enabled a qualitative assessment of erosion potential, as well as, the actual erosion in Carinhanha Basin. The area has a low rate of erosion due to its current natural vegetation cover. However, the scenario would change if modifications continue to be done in natural vegetation. The results show the spatial distribution of susceptible areas where conservation practices can be suitable in preventing loss of soil by erosion.

Keywords: laminar erosion, USLE, Cerrado Biome, Geographic Information System.

\section{Bibliografia}

ARAÚJO JUNIOR, G.J.L.D. (2003). Aplicação dos modelos EUPS e MEUPS na Bacia do Ribeirão Bonito (SP) através de técnicas de sensoriamento remoto e geoprocessamento. São José dos Campos-SP, 122p. Dissertação de Mestrado. Instituto de Pesquisas Espaciais - INPE.

BERTONI J. LOMBARDI NETO, F. Conservação do solo. São Paulo: Ed. Ícone 1990. 355p.

BORGES, K.M.R. (2009). Avaliação da susceptibilidade erosiva da Bacia do Rio Carinhanha (MG/BA) por meio da EUPS - Equação Universal de Perda de Solos. Dissertação de Mestrado, Departamento de Geografia, UnB.

CAMAPUM DE CARVALHO, J.; SALES, M.M.; SOUZA, N.M.; MELO, M.T.S. (Org.). (2006). Processos erosivos no Centro-Oeste Brasileiro. Brasília: FINATEC, 464p.

CAMPOS, J.E.G.; DARDENNE, M.A. (1997). Estratigrafia e sedimentação da Bacia Sanfranciscana: uma revisão. Revista Brasileira de Geociências, v. 27, n. 3, p. 269-282.

CARVALHO, N.O. (1994) Hidrossedimentologia prática. Brasil, Ministério de Minas e Energia, CPRM, Minerais, Rio de Janeiro. 371p. 
CHAVES, H.M.L. (1994). Estimativa da erosão atual e potencial no Vale do São Francisco. In: Relatório Final de Consultoria. Brasília: CODEVASF - FAO, 35p.

CREPANI, E.; MEDEIROS, J. S.; AZEVEDO, L. G.; HERNANDEZ FILHO, P.; FLORENZANO, T. G.; DUARTE, V. (2001). Sensoriamento Remoto e Geoprocessamento Aplicados ao Zoneamento EcológicoEconômico e ao Ordenamento Territorial. São José dos Campos: INPE, 80 p. INPE /8454/RPQ/722.

DARDENNE, M.A. (1978). Síntese sobre a estratigrafia do Grupo no Brasil Central. In:, Congresso Brasileiro de Geologia, 30. Recife: SBG, Anais, v. 2, p. 597-610.

DESMET, P.J.J.; GOVERS, G.A. (1996). GIS Procedure of automatically calculating the USLE LS factor on topographically complex landscape units. Journal of Soil and Water Conservation, v. 51, n. 5, p. 427-433.

FARINASSO, M.; CARVALHO JUNIOR, O.A.; GUIMARÃES, R.F.; GOMES, R.A.T.; RAMOS, V.M. (2006). Avaliação qualitativa do potencial de erosão laminar em grandes áreas por meio da EUPS Equação Universal de Perdas de Solos utilizando novas metodologias em SIG para os cálculos dos seus fatores na região do Alto Parnaíba - PI-MA. Revista Brasileira de Geomorfologia - Ano 7, n. 2, p. 73-85, 2006.

HUTCHINSON, M.F. (1989). A new procedure for gridding elevation and stream line data with automatic removal of spurious pits. In: Journal of Hydrology, 106: 211-232, 1989.

INSTITUTO BRASILEIRO DE GEOGRAFIA E ESTATÍSTICA - IBGE. (1992). Manual técnico da vegetação brasileira. Rio de Janeiro, 92p. (Manuais técnicos em geociências, 1).

INSTITUTO BRASILEIRO DE GEOGRAFIA E ESTATÍSTICA - IBGE. (1993). Mapa de Vegetação do Brasil - Escala 1:5.000.000. Rio de Janeiro, 1 carta.

LEPRUN, J. C. (1998). Manejo e conservação de solos no Nordeste. Recife: SUDENE.

LOMBARDI NETO, F.; MOLDENHAUER, W.C. (1992). Erosividade da chuva: sua distribuição e relação com perdas de solo em Campinas-SP. Bragantia. Campinas, v. 51, n. 2, p. 189-196, 1992.

MATA, C.L.; CARVALHO JÚNIOR, O.A.; CARVALHO, A.A.F.; GOMES, R.A.T.; MARTINS, E.S.; GUIMARÃES, R.F. (2007). Avaliação multitemporal da susceptibilidade erosiva na bacia do rio Urucuia (MG) 
por meio da Equação Universal de Perda de Solos. Revista Brasileira de Geomorfologia - Ano 8, $\mathrm{n}^{\circ} 2$.

PINESE JUNIOR, J.F.; CRUZ, L.M.; RODRIGUES, S.C. (2008). Monitoramento de erosão laminar em diferentes usos da terra, Uberlândia MG. Sociedade e Natureza (Online), Uberlândia, v. 20, n. 2, dez. 2008. Disponível

$<$ http://www.scielo.br/scielo.php?script=sci_arttext\&pid=S1982-

45132008000200010\&lng=pt\&nrm=iso $>$. $\quad$ doi: $\quad 10.1590 /$ S198245132008000200010.

SILVA, V.C. (2004). Estimativa da erosão atual da bacia do Rio Paracatu (MG/GO/DF). Pesquisa Agropecuária Tropical, v. 34, n. 3, p. 147-159.

STEIN,D.P.; DONZELLI,P.L.; GIMENEZ,A.F.; PONÇANO,W.L.; LOMBARDI NETO,F. (1987). Potencial de erosão laminar, natural e antrópico, na Bacia do Peixe-Paranapanema. Anais $4^{\circ}$ Simpósio Nacional de Controle de Erosão. Marília-SP: ABGE / DAEE, p. 105-135.

RODRIGUES, S.C. (2002). Impacts of Human Activity on Landscapes in Central Brasil. A Case Study in the Araguari Watershed. Geographical Research, Australia, v. 40, n. 2, p. 167-178.

SANO, E.E.; ROSA, R.; BRITO, J.L.S.; FERREIRA, L.G. (2009). Land cover mapping of the tropical savanna region in Brazil. Environmental Monitoring and Assessment, v. 1, p. 1-12.

TARBOTON, D.G.A. (1997). New method for the determination of flow directions and up slope areas in grid digital elevation models. Water Resources Research. v. 33, p. 309-319.

TRICART, J. (1977). Ecodinâmica, Rio de Janeiro: IBGE-SUPREN, 91p. (Recursos Naturais e Meio Ambiente).

VILAR, O.M., PRANDI, E.C. (1993). Erosão dos solos, in: Solos do interior de São Paulo. São Carlos-SP: ABMS e USP/SC, p. 177-206.

WISCHMEIER, W.H.; SMITH, D.D. (1978). Predicting rainfall erosion losses; a guide to consevation planning. Washington: U.S. Departament of Agriculture, 58p. (Agriculture Handbook, n. 537). . (1959). Rainfall energy and its relationship to soil loss.

Trans. American Geoph. Un., Washington, v. 39, p. 285-291. 